\title{
Numerical investigation on the effect of condensate layer formation around large-size components during vapour phase soldering - MANUSCRIPT
}

\author{
Balázs Illés ${ }^{1), 2)}$, Attila Géczy ${ }^{1), 2)}$, Oliver Krammer ${ }^{1), 2)}$, Karel Dušek $^{2)}$ and David Bušek ${ }^{2)}$ \\ ${ }^{1)}$ Department of Electronics Technology, Budapest University of Technology and Economics, \\ Budapest, Hungary \\ ${ }^{2)}$ Department of Electrotechnology, Czech Technical University in Prague, Czech Republic \\ billes@ett.bme.hu
}

\begin{abstract}
The reflow soldering process of large size components was always problematic in microelectronics manufacturing due to the possibility of component displacement failures after soldering; like tombstone formation or skewing, which can be traced back to the different heating of the opposite component sides. During vapour phase soldering, the efficiency of heat transfer highly depends on the thickness of the condensate layer. In this paper, the inhomogeneity of condensate layer formation and its effects were investigated at large size components during vapour phase soldering by numerical simulations. For this purpose, a 3D computational fluid dynamic model was established. According to the condensate layer formation in different cases, the onset differences in the melting of the solder alloy at the opposite leads of the component were calculated. By the results, the risk of the component displacement before reflow soldering was analysed. It was found, that the congestion of the condensate layer around the large size components can cause considerable differences in the onset of the solder alloy melting, which can yield in component displacement failures after soldering. The extent of difference in onset of melting depends on the location of the component on the substrate and on the applied soak temperature. Keep-out zones on the substrate were suggested to reduce the possibility of the component displacement failures during the vapour phase soldering process.
\end{abstract}

Keywords - Vapour Phase Soldering, condensation, condensate layer, component displacement, surface tension.

\section{Introduction}

The condensation based heat transfer is widely used in everyday life for heating purposes like facility heating with heat pumps [1], as well as for cooling purposes such as spiral wound heat 
exchangers in large-scale liquid natural gas plants. [2], cooling space vehicles by loop heat pipes with steam jet pump [3] or microelectronics with heat pipes [4]. The Vapour Phase Soldering (VPS) is a reflow soldering method. It is considered as an alternative of convection and infrared reflow soldering methods in the electronics industry [5]. The basic steps of the reflow soldering are the followings: first, the solder in paste is deposited onto the solder pads of a Printed Circuit Board (PCB) by stencil printing. Then Surface Mounted Devices (SMDs) are placed onto solder deposits. Finally, the whole assembly is heated up over the melting point of the applied solder alloy, which forms the joints between the leads of the components and the pads of the PCB [6].

In the VPS technology, condensation heating is used for reflow soldering. During the process, a heat transfer fluid is heated at the bottom of a tank to its boiling point; then due to the evaporation of the fluid, a vapour space begins to develop in the workspace. When the vapour space is ready for soldering, the assembly is immersed into it. The vapour starts to condense on the assembly and forms a continuously moving condensate layer (the condensate layer is flowing down from the PCB). This layer transfers the latent heat of condensing mass and the conducted heat from surrounding vapour to the assembly, which is heated up the boiling point of the heat transfer fluid. The efficiency of the heat transfer depends mainly on the thickness of the condensate layer [6]. After the melting and wetting of the solder alloy, the assembly is lifted out from the process zone in order to cool down, and to solidify the solder joints. Nowadays, the most widely applied heat transfer fluid is Galden, which contains ether chains closed with carbon-fluorine bonds (Perfluoropolyether, PFPE) [7].

The main advantage of condensation heating for soldering is the lack of overheating [8] because of the limitation of the boiling point. The main disadvantage is the intensive heat transfer (it can be 2-3 times higher than in a convection oven [10]), which can also cause soldering failures like voiding, paste sputtering, and tombstone failures [10]. In the literature, most researchers investigated the practical use of the technology. Leicht et al. decreased the heat transfer coefficient of the VPS process by utilising non-saturated vapour [11]. Dumitru et al. investigated the effect of heating of VPS process on the mechanical characteristics of PCBs [12]. Branzei et al. studied the relationship between the heat transfer and the mechanical strength of the solder joints [13]. Synkiewicz et al. demonstrated the influence of the vacuum VPS thermal profile on the quality and reliability of solder joints for thermogenerators [14]. Livovsky and Pietrikova designed a real-time thermal profiling method for VPS process in order to approach defect-free reflow soldering [15]. Although the heat transfer of VPS process is considered to be generally uniform (compared to the infrared or convection type soldering 
systems), it was also shown that the thickness of condensate changes considerably on the surface of the PCB which results in spatial differences in heat transfer [6].

Using large size SMD components like power FETs, capacitors or inductors (having linear dimensions over $5 \mathrm{~mm}$ ) is common in modern electronics devices. However, reflow soldering process of such a large-size components was always problematic for the industry, because of the higher risk of component displacement type soldering failures, like tombstone formation or skewing, which results in open solder joints [16]. The component displacement during the soldering can be traced back to the differences in wetting between the leads of the component [17]. The non-balanced wetting force (originating from the high surface tension of the lead-free solder alloys) [18, 19] can move the component away from its proper location. The most prevalent problems, which can cause wetting defects, are uneven heating during soldering, oxidized or contaminated leads [20] and differences in printed solder paste volume at the leads [21]. Furthermore, not appropriate pad design (like imbalanced thermal mass distribution or asymmetrically connected heat sinks) or too large heating rate in the ramp up section of the thermal profile can result in imbalance of the solder alloy melting at the different leads of the component $[21,22]$. This can definitely perturb the wetting balance, and can yield in component displacement after soldering.

Unfortunately, during the VPS process, the large components can cause congestion of the flowing condensate layer, resulting in both the accumulation of the heat transfer fluid and the variation of the heat transfer locally. This phenomenon might cause difference in the onset of solder alloy melting at the different leads of the component, which can also yield in a component displacement / skewing failures after soldering. The aim of our investigations was to examine the condensate layer formation around large size components, calculate the imbalance in the melting of the solder alloy and predict the possible component movement failures.

\section{The applied numerical model}

A 3D Computational Fluid Dynamics (CFD) model was established to describe the condensate layer formation and the temperature change of assemblies during VPS process. The model is based on the general Navier-Stokes (NS) equations and the condensate flow is supposed to be laminar. 


\subsection{Physical description of the model}

After immersing the room temperature assembly into the vapour space, the vapour starts to condensate onto its surface and forms a condensate layer. The condensing Galden gives the latent heat and the internal energy of the condensing mass to the condensate layer:

$$
Q_{c}=\left(h+C_{S} \cdot T_{b}\right) \cdot m_{c}
$$

where $h$ is the latent heat of the Galden $[\mathrm{J} / \mathrm{kg}], m_{c}$ is the condensing mass $[\mathrm{kg}], C_{S}$ is the specific heat capacity $[\mathrm{J} /(\mathrm{kg} \cdot \mathrm{K})]$ and $T_{b}$ is the given boiling temperature of the Galden liquid $[\mathrm{K}]$. The energy increase due to the condensation introduces the heat flux into the condensate layer:

$$
q_{c}=\lambda \cdot \frac{\partial \overline{T_{i}}}{\partial x_{i}} \quad\left[\mathrm{~W} / \mathrm{m}^{2}\right]
$$

where, $\lambda$ is the specific heat conductivity $[\mathrm{W} /(\mathrm{m} \cdot \mathrm{K})]$ and $T$ is the temperature $[\mathrm{K}]$. Since the amount of the condensing mass depends on the amount of heat that the condensate layer can conduct away, the condensing mass can be calculated by Eq. (1) and (2):

$\frac{\partial m_{c}}{\partial t}=\left(\frac{\lambda}{h+C_{S} \cdot T_{b}}\right) \cdot \frac{\partial \bar{T}_{i}}{\partial x_{i}} \quad\left[\mathrm{~kg} /\left(\mathrm{s} \cdot \mathrm{m}^{2}\right)\right]$

The condensate layer formation (the flow) was described on two levels. A full dynamic approach at board level, and a half-dynamic approach was introduced at component level.

In the full dynamic approach, the condensate layer flow is initiated by the hydrostatic pressure differences in condensate layer:

$$
p_{h}=\left(\rho_{l}-\rho_{v}\right) \cdot l \cdot g \quad[\mathrm{~Pa}]
$$

where $\rho_{l}$ and $\rho_{v}$ are the densities of the Galden liquid and the vapour $\left[\mathrm{kg} / \mathrm{m}^{3}\right], g$ is the gravitational acceleration $\left[\mathrm{m} / \mathrm{s}^{2}\right]$ and $l$ is the height of the condensate layer $[\mathrm{m}]$. The condensate is supposed to be homogenous from the density point of view; therefore, the continuity equation for incompressible fluids can be applied:

$$
\frac{\partial \overline{u_{j}}}{\partial x_{i}}=0
$$

where $u$ is the velocity $[\mathrm{m} / \mathrm{s}]$. The NS equation for incompressible, Newtonian fluids in a laminar flow space is used:

$$
\frac{\partial \overline{u_{i}}}{\partial t}+\overline{u_{j}} \frac{\partial \overline{u_{i}}}{\partial x_{j}}=g_{i}-\frac{1}{\rho_{l}} \frac{\partial \overline{p_{h}}}{\partial x_{i}}+v \frac{\partial}{\partial x_{j}} \frac{\partial \overline{u_{j}}}{\partial x_{j}}
$$


where $v$ is the kinematic viscosity $\left[\mathrm{m}^{2} / \mathrm{s}\right]$. In the condensate layer, conductive and convective energy transport is calculated by the heat equation:

$$
\frac{\partial \bar{T}}{\partial t}+\overline{u_{j}} \frac{\partial \bar{T}}{\partial x_{j}}=\frac{\lambda}{\rho C_{s}} \frac{\partial}{\partial x_{j}} \frac{\partial \bar{T}}{\partial x_{j}}
$$

The lateral dimensions of the component are one order of magnitude smaller than the lateral dimensions of the board. Therefore, the application of full dynamic approach in the calculation of the condensate layer flow at the component level is not recommended, since considerable increase in the time of calculation is expected. So at component level a half-dynamic approach was introduced. The dynamic flow field of the condensate layer is not calculated, only the mass transfer is estimated for approximating the steady-state condensate thicknesses both on the walls and on the top of the component. The steady-state condensate thicknesses $(\tau)$ are calculated in each calculation step according to Bejan's approximation [23]:

$$
\begin{aligned}
& \tau_{\text {max_wall }_{-}}=1.28 /\left[\frac{\left(h+3 / 8 C_{s}\left(T_{b}-T_{l}\right)\right)\left(\rho_{l}-\rho_{v}\right) g}{\lambda_{l}\left(T_{b}-T_{l}\right) v_{l}(L / 2)^{2}}\right]^{1 / 5} \\
& \tau_{\text {max } \_ \text {wall }_{1}}=\left[\frac{\lambda_{l}\left(T_{b}-T_{l}\right) v_{l}}{\left(h+3 / 8 C_{s}\left(T_{b}-T_{l}\right)\right)\left(\rho_{l}-\rho_{v}\right) g} 4 z\right]^{1 / 4}
\end{aligned}
$$

where $T_{l}$ is the temperature of condensate layer $[\mathrm{K}], L$ is the characteristic length of the top surface (practically the half width of a surface) $[\mathrm{m}]$ and $z$ is the length of the wall [m].

\subsection{Numerical solution and parameters of the model}

The numerical conversion of the partial differential equations was performed by FDM (Finite Difference Method), and it was solved by explicit FTCS (Forward Time Central Space) algorithm. The general numerical form of FTCS is the following:

$$
\frac{\partial v}{\partial t}+\frac{\partial v}{\partial x}+\frac{\partial v^{2}}{\partial^{2} x}=0 \underset{F T C S}{\longrightarrow} \frac{v_{i}^{k+1}-v_{i}^{k}}{\Delta t}+\frac{v_{i+1}^{k}-u_{i-1}^{k}}{2 \Delta x}+\frac{v_{i+1}^{k}-2 v_{i}^{k}+v_{i-1}^{k}}{\Delta x^{2}}=0
$$

where $v$ is a general variable, $t$ is the time [s], $x$ is the space [m] and $i$ and $k$ are the indices of the numerical grid and time steps respectively. The mass transfer estimation bases on in the half-dynamic model that each cell gives the excess amount of the condensate $\left(\tau_{\max }-\tau_{\mathrm{n}}\right)$ to the neighbouring cell(s). The affected neighbouring cell(s) are appointed by the direction of the gravitational force field at the given part of the model. The transferred mass is calculated by eq. (11): 
$\Delta m_{n}=\left.\left(\tau_{\max }-\tau_{n}\right) \rho_{l} x_{n} y_{n}\right|_{\tau_{\max }>\tau_{n}}[\mathrm{~kg}]$

where $n$ is the index of the mesh, $x_{n}$ and $y_{n}$ are the lateral dimensions of the cell [m].

During the calculations a 4036 SMD PET capacitor (size: $10 \times 9 \times 5.5 \mathrm{~mm}$ ) was used for the investigations. This component belongs to the family of polymer film capacitors. The base of the component is Polyethylene terephthalate (PET - as a dielectric material) with Al electrodes. The components have cap type metallization prepared from $150 \mu \mathrm{m}$ thick Al sheets and covered by $\mathrm{Sn}$ surface finishing. The board was an FR4 type PCB with linear dimensions of $80 \times 80 \times 1.5 \mathrm{~mm}$. The applied solder pads were built up from $17 \mu \mathrm{m}$ thick copper layer covered by $2 \mu \mathrm{m}$ thick chemical tin layer and they had $9 \times 2.4 \mathrm{~mm}$ dimensions (according to the component manufacturer recommendations). SAC305 solder paste deposited with $125 \mu \mathrm{m}$ thickness and HS230 type Galden (boiling point $230^{\circ} \mathrm{C}$ ) was applied during the calculations. For VPS use, a more advanced soak type thermal profile was set with three different soak temperatures: $140{ }^{\circ} \mathrm{C}$ (low), $160^{\circ} \mathrm{C}$ (normal) and $180^{\circ} \mathrm{C}$ (high) soak temperatures. This profile can be assumed as general type of heating for other reflow methods in the electronics industry, however for VPS, special control is required to approximate this plot (as seen in Figure 1.). The paper focuses further investigation on the soak and ramp periods, critical for reflowing the deposited solder alloy.

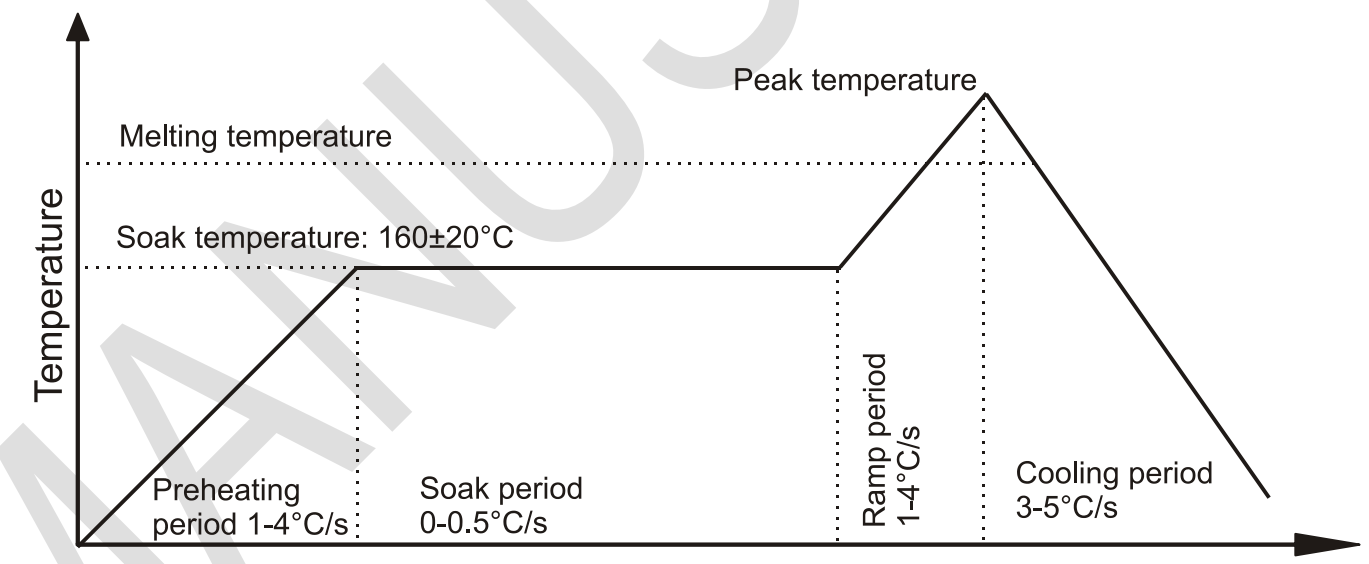

Time

Fig. 1. General soak type thermal profile of the reflow soldering.

The applied material properties are collected in Tab. 1. The heat conductivity of the solder paste is calculated according to the Maxwell model for colloid suspensions [25]:

$$
\lambda_{\text {paste }}=\lambda_{w}\left(1+\frac{3\left(\lambda_{S A C} / \lambda_{w}-1\right) v_{f}}{\left(\lambda_{S A C} / \lambda_{w}+2\right)-\left(\lambda_{S A C} / \lambda_{w}-1\right) v_{f}}\right) \quad[\mathrm{W} /(\mathrm{m} \cdot \mathrm{k})]
$$


where $\lambda_{\mathrm{w}}$ and $\lambda_{\mathrm{SAC}}$ are the specific heat conductivities $[\mathrm{W} /(\mathrm{m} \cdot \mathrm{K})]$ of the carrier liquid (water) and the SAC alloy; and $v_{f}$ is the volume friction ( $\sim 0.5$ in this suspension).

Table 1. Physical properties of the applied materials.

\begin{tabular}{c|cccccc}
\hline \hline Material $/$ Property & Galden & FR4 & PET & $\mathrm{Cu}$ & SAC & Al \\
\hline Density $\left[\mathrm{kg} / \mathrm{m}^{3}\right]$ & $1820 / 19.96^{* 1}$ & 2100 & 1400 & 8960 & $4185 / 7370^{* 2}$ & 2700 \\
\hline Heat Cond. $[\mathrm{W} /(\mathrm{m} \cdot \mathrm{K})]$ & 0.065 & 0.23 & 0.3 & 385 & $2.29 / 58^{* 2}$ & 220 \\
\hline Heat Cap. $[\mathrm{J} /(\mathrm{kg} \cdot \mathrm{K})]$ & 973 & 570 & 1200 & 385 & $2542 / 2320^{* 2}$ & 900 \\
\hline Latent Heat $[\mathrm{KJ} / \mathrm{kg}]$ & 67 & - & - & - & $677^{[24]}$ & - \\
\hline Kinematic viscosity $\left[\mathrm{m}^{2} / \mathrm{s}\right]$ & $4.4 \mathrm{E}-6$ & - & - & - & $2.31 \mathrm{E}-7$ & - \\
\hline Surface tension $[\mathrm{N} / \mathrm{m}]$ & - & - & - & - & 0.55 & - \\
\hline
\end{tabular}

*1 liquid / vapour state

*2 paste/ liquid state

*3 at room temperature

The investigated component locations on the PCB were selected according to symmetry of the substrate and our previous experience [6]. The variation in the condensate layer thickness and the change in the flow velocity of the condensate layer are nearly symmetrical from the middle of the PCB towards the edges. Their gradients have the maximum values from the middle of the PCB towards the edges, in lateral directions. Therefore, as a worst-case analysis, the investigated component locations are selected on concentric squares from the middle of the PCB and the position of the components are parallel with the axes of the concentric squares. Six different locations were selected: A) 1/4 PCB size, B) 1/2 PCB size, and C) 3/4 PCB size from the middle of the PCB on the middle axis; and D)1/4 PCB size, E) 1/2 PCB size F) 3/4 PCB size from the middle of the PCB on the diagonal (Fig. 2). During each investigation, only the component and the pads are placed on the PCB, no any other wiring or other object was applied, in order to avoid the disturbing effects. 


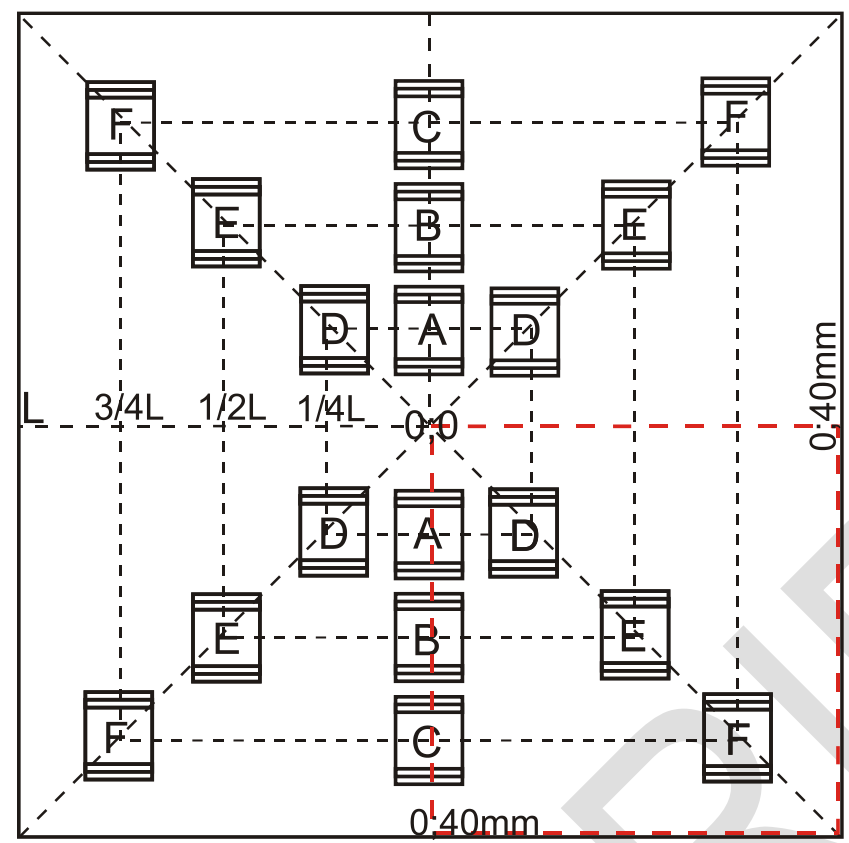

Fig. 2. Investigated component positions on the PCB.

The model discretization was performed considering the Courant-Friedrichs-Lewy (CFL) condition [26].

Cell dimensions vary between $1-300 \mu \mathrm{m}$ in the non-uniform grid, and dynamic cell thicknesses are used for the condensate layer. The complete model consists of $\sim 70.000$ cells. Adaptive time steps are used between $0.1-0.4 \mathrm{~ms}$. The numerical model was solved in MATLAB software. The calculations were done only for a quarter of the whole structure due to symmetry reasons (marked by red square in Fig. 2). Later the results of this quarter will be shown in the figures.

The initial conditions of the calculations were the following: the calculations started after the soak period of the investigated soak temperatures $\left(140,160\right.$ and $\left.180^{\circ} \mathrm{C}\right)$, it is supposed that to the end of the soak, the temperature distribution is homogenous in the system. As an initial condition saturated vapour space is set to the work zone. Condensate layer is not present before the start of the process, so initial conditions for the condensate layer are $u(0)=0 \mathrm{~m} / \mathrm{s}, p_{h}=0 \mathrm{~Pa}$ and $m(0)=0 \mathrm{~kg}$.

The boundary conditions were the following: there is no heat and mass transfer between the VPS system and the environment. The PCB assembly is consuming the vapour space due to the condensation, what the VPS oven tries to refill. The characteristics of the vapour concentration change during the soldering were investigated by differential pressure sensors (see details about the 
measurement method in [27]) in the case of the different soak (starting) temperatures. The results can be seen in Fig. 3.

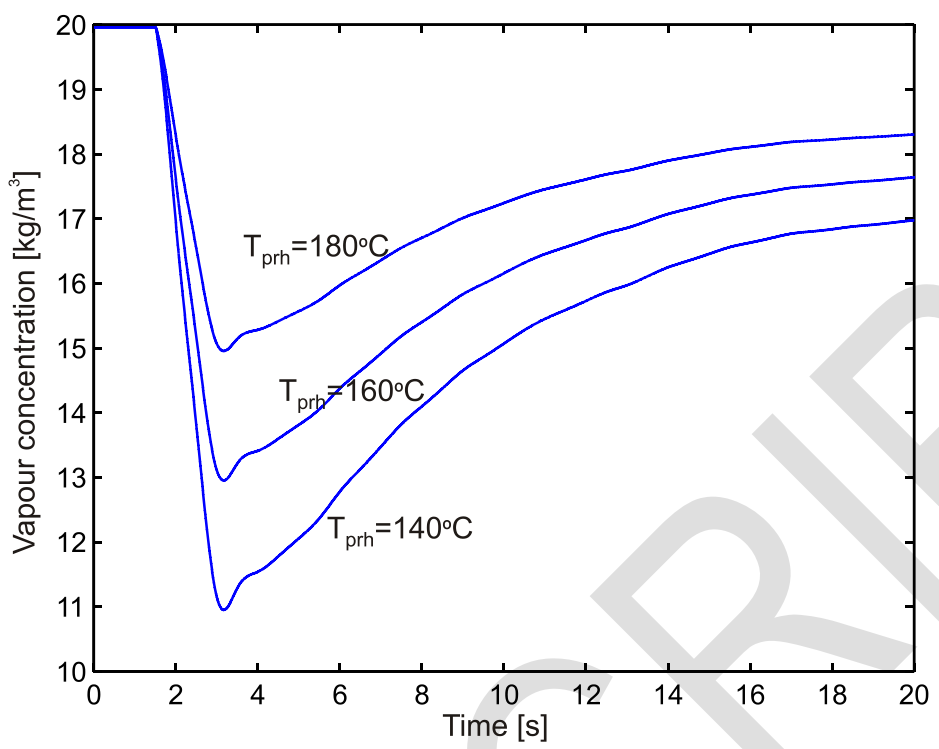

Fig. 3. Vapour concentration change during the soldering process in the case of the different soak temperatures.

The condensation of the vapour stops inherently when the temperature of the condensate layer reaches the dew point $\left(T^{d p}\right)$; the applied dew point model is the following [27]:

$$
T^{d p}=T-46.5 \cdot\left(1-\frac{\rho}{\rho^{s t}}\right)
$$

where $\rho^{s t}$ is the saturated vapour concentration $\left[\mathrm{kg} / \mathrm{m}^{3}\right]$. Boundary conditions of the condensate layer are the following:

$$
\frac{\partial T}{\partial \bar{r}}=\left.0\right|_{r \rightarrow \text { bound. }} ; \underset{r \rightarrow \text { bound. }}{-\lim _{h}} p_{h}=0 ; \lim _{r \rightarrow \text { bound. }} v=\infty
$$

The numerical model was validated with the measurement of temperature on the pure FR4 substrate over the ramp period of the thermal profile (Fig. 1). Measurements were performed with Ktype thermocouples (TCs) having an absolute measurement accuracy of $\pm 0.5^{\circ} \mathrm{C}$. TCs were embedded into the FR4 substrate from the back side to avoid the perturbation of condensate layer formation on the top side. Temperature changes were measured at the centre and at one corner of the substrate. The validation results are shown in Fig. 4. The calculated results correspond sufficiently to the measured 
values. The breaks in the curves are caused by reaching the dew point, where the dynamics of heating is lower from. The measured temperature values showed less dynamic nature than the calculated ones, which is probably because of minor measurement inaccuracies.

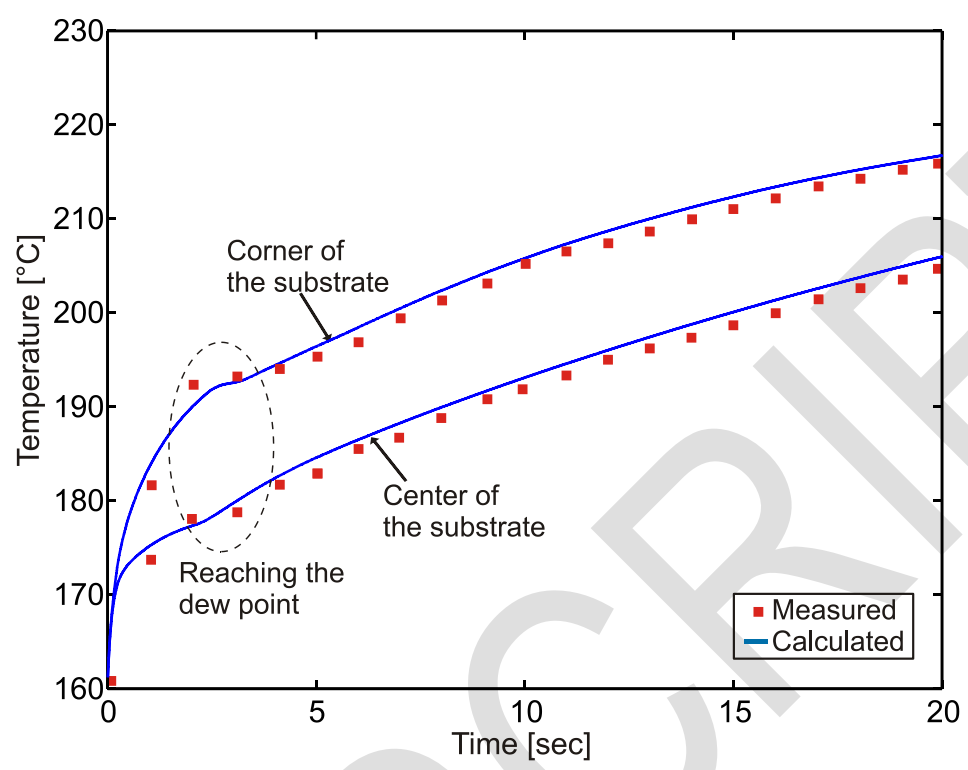

Fig. 4. Comparison of the measured and calculated temperature change of the substrate during the ramp period of the thermal profile.

\section{RESUlTS AND DisCuSSIONS}

In the first step, the condensate layer formation on the PCB was examined. Fig. 5 shows the flow field on the PCB in the case of B component location at $1 \mathrm{~s}$ and at $4 \mathrm{~s}$ after the start of the soldering process. The condensate flowing down from the component has significant effect on the flow field. The most of the condensate flows down from the component at the start of the process between 0.1$1 \mathrm{~s}$, since the condensation is the most intense at the beginning of the process when the assembly is the coldest. Between 0-0.1s, the condensate only accumulates on the component; the flowing down starts only after, when the surface tension could not keep the condensed amount further. The large amount of down-flowing condensate introduces such a high flow velocity around the component as the flow velocity at the edges of the PCB (Fig. 5a)). In addition, the flow turns back behind the component towards the middle of the PCB (Fig. 5a)). After $4 \mathrm{~s}$, the amount of the down-flowing condensate from the component is smaller and the flow field becomes near steady (Fig. 5 b)). The flow of the condensate layer tries to bypass the component which results in a much slower flow velocity behind the component than in front of it towards the edges of the PCB (Fig. 5 b)). 


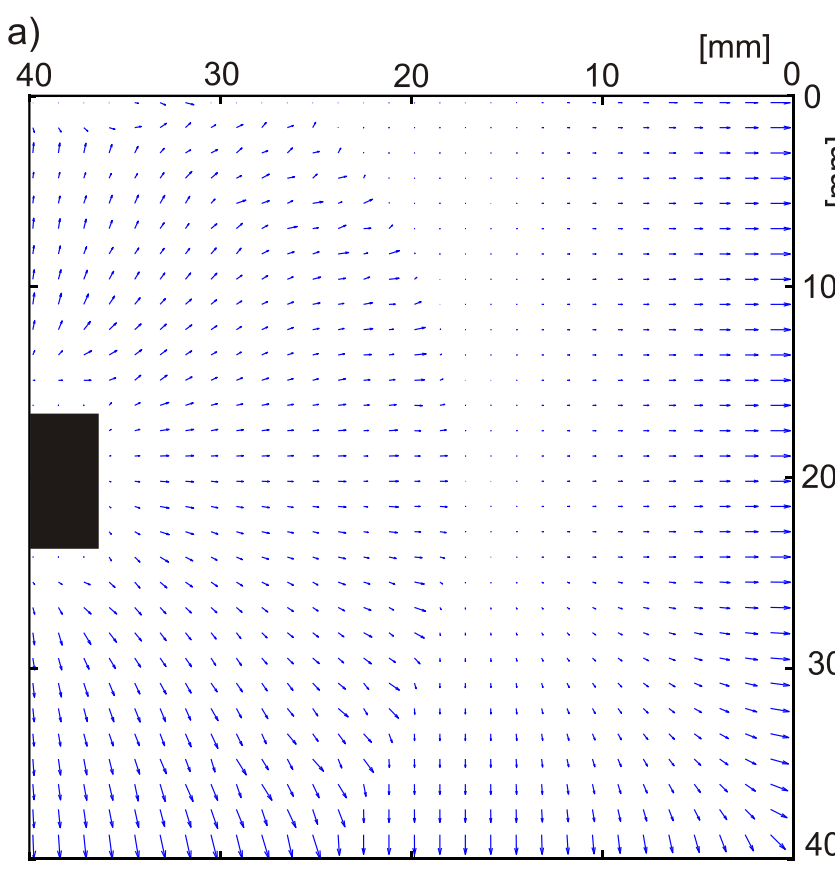

b)

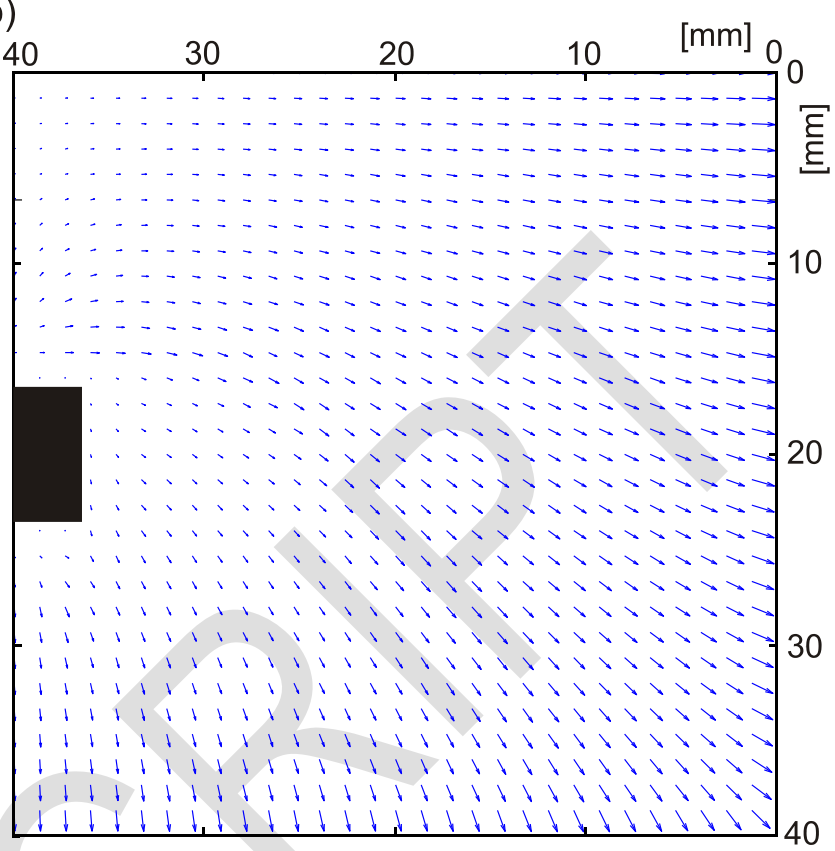

Fig. 5. Flow field analysis of the condensate layer on the PCB in the case of B component location: a) at $1 \mathrm{~s} ; \mathrm{b})$ at $4 \mathrm{~s}$. 

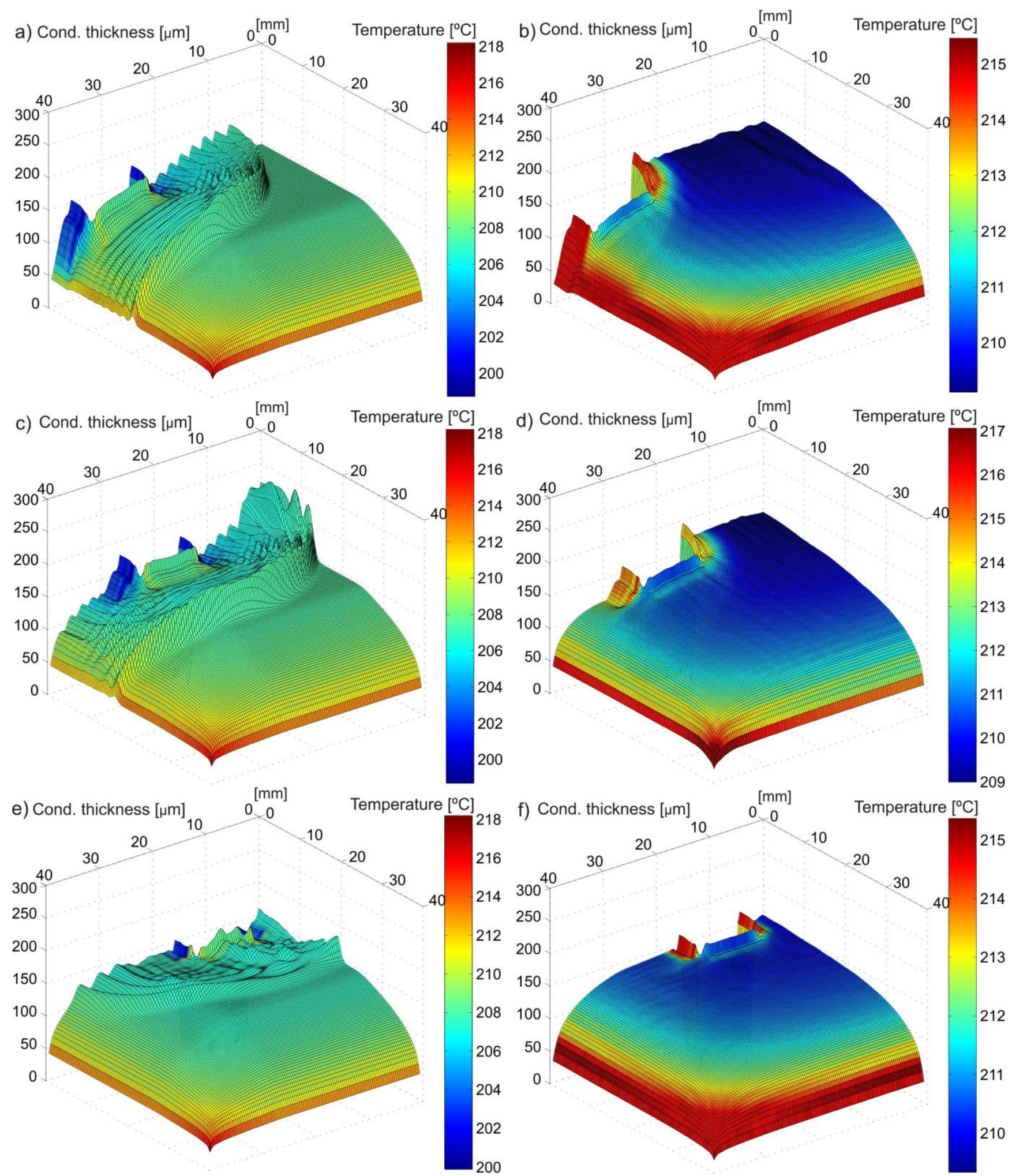

Fig. 6. Condensate layer thickness with significant ripples and temperature distribution in the case of $160{ }^{\circ} \mathrm{C}$ soak temperature: a) location $\mathrm{C}$ at $1 \mathrm{~s}$; b) location $\mathrm{C}$ at $4 \mathrm{~s}$; c) location $\mathrm{B}$ at $1 \mathrm{~s}$; d) location $\mathrm{b}$ at $4 \mathrm{~s}$; e) location $\mathrm{A}$ at $1 \mathrm{~s} ;$ f) location $\mathrm{A}$ at $4 \mathrm{~s}$. 
In Fig 6 the condensate layer on the PCB can be seen with different component locations at different time points. (The PCB and the component is not shown, but their positions are clearly visible in Fig. 6) The down-flowing condensate from the component cause ripples in the condensate layer on the PCB. The perturbation of the condensate layer by the down-flowing condensate depends on the component location. The perturbation is the smallest when the component is close to the middle of the PCB (Fig. 6e)), since then the down-flowing condensate can leave the PCB surface easily without reflections at the middle of the PCB. As the component is located closer to the edges (Fig. 6a), c)) the wave reflections from the middle of the PCB are higher which causes higher perturbation of the condensate layer. The highest wave reaches $250 \mu \mathrm{m}$, while the average condensate thickness on the PCB is $130-150 \mu \mathrm{m}$ during the whole process. Up to $4 \mathrm{~s}$, the ripple waves almost disappear in all cases and the amount of the down-flowing is as small that it is almost not visible in the results (Fig. 6 b), d), f)). The congestion of the condensate layer behind the component causes considerable condensate layer difference between the solder joints positions. The maximum of the condensate thickness difference is $\sim 100 \mu \mathrm{m}$ at $2 \mathrm{~s}$, -however this relatively large difference is caused by the disturbing effect of the down-flowing Galden liquid - but the average is still $22 \mu \mathrm{m}$ during the whole process.

After the condensate layer is stabilized ( $4 \mathrm{~s})$ the temperature distribution of the condensate layer is canonical [6, 27], the coldest part is at the middle and the hottest part is at the edge of the PCB (Fig. 6). The maximum temperature difference is $7-10{ }^{\circ} \mathrm{C}$ during the whole process. However, it is interesting that at the beginning of the process $(0.1-3 \mathrm{~s})$, the condensate layer at the solder joints is colder than the average condensate layer temperature (Fig. 6 a), c) d)), but after $3 \mathrm{~s}$ this tendency turns back (Fig. 6 b), d) e)). The changes of the average temperatures in the whole system were analyzed in order to understand this phenomenon (Fig. 7). According to the results, the down-flowing condensate from the component leads has considerable effect on the temperature of the condensate layer on the PCB. At the beginning $(0-3.5 \mathrm{~s})$ of the process, the temperature of the down-flowing condensate from the component leads (Fig. 7, curve 6) is colder than the average temperature of the condensate layer on the PCB (Fig. 7, curve 2) and this cools down the condensate layer locally at the solder joints (Fig. 7, curve 3). After $3.5 \mathrm{~s}$ the temperature of the down-flowing condensate from the component leads exceed the average condensate layer temperature and previous the tendency changes. During the whole process, the temperature of the condensate layer over the solder joints (Fig. 7, curve 2) follows curve 6 closely. 


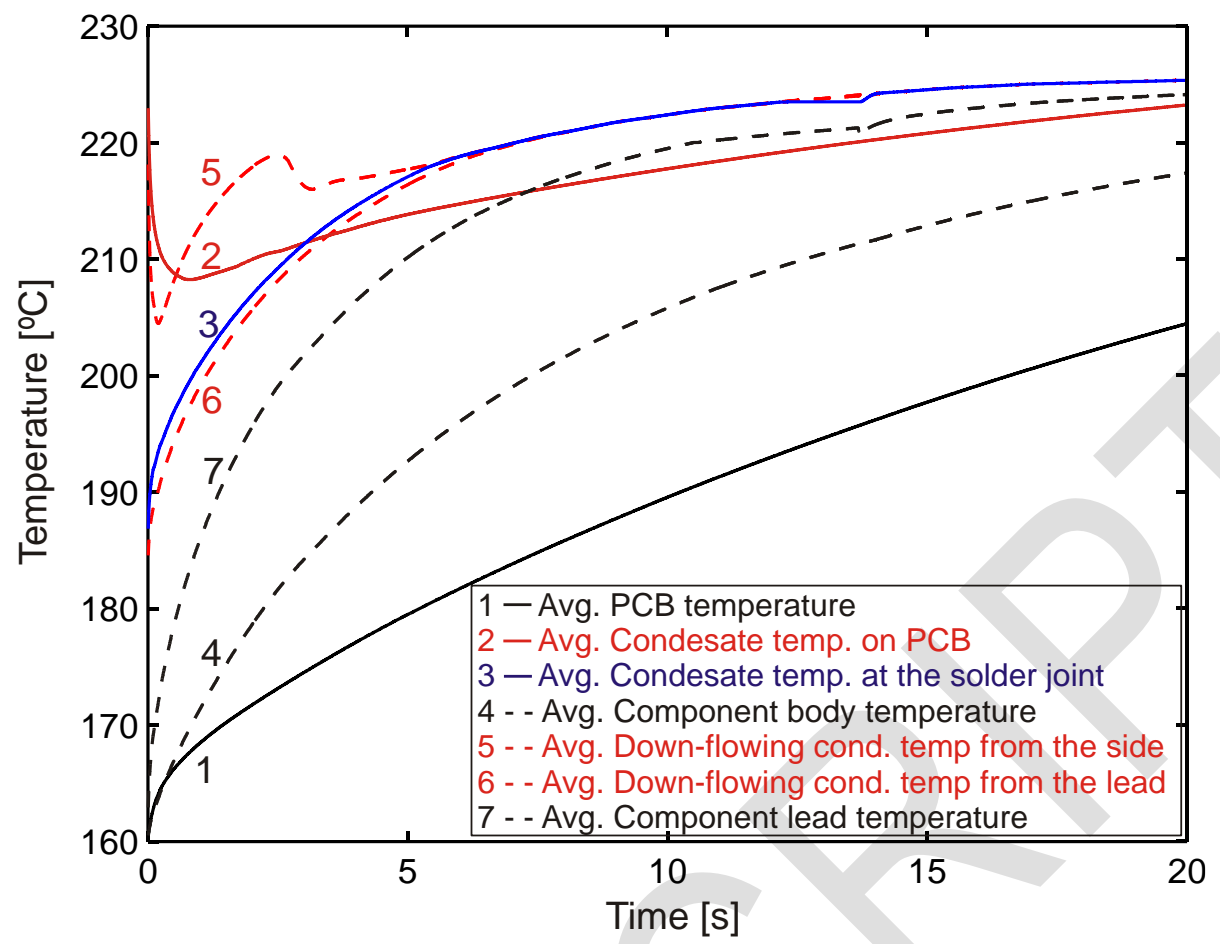

Fig. 7. Change of the average temperatures in the whole system.

The thermal parameters of the PET (component body) and the FR4 (PCB body) are similar (see Tab. 1), however the component (Fig. 7, curve 4) heats up much faster than the PCB (Fig. 7, curve 1). This phenomena is caused by the relatively large vertical surfaces of the component where the heat transfer is much higher than on the horizontal surfaces [23]. Nevertheless, the component itself cannot give heat to the condensate layer on the PCB, the average temperature of the component leads (Fig. 7, curve 7) are always under the temperature of the condensate layer at the solder joints (Fig. 7, curve 3). The average temperature of the down-flowing condensate from the component side (Fig. 7, curve 5) is even higher than from the component leads (Fig. 7, curve 6), however no further effect of this is visible on the condensate layer on the PCB (Fig. 6).

The temperature analyses of the component show that at the beginning of the process the leads of the component (as well as the condensate on them) are a bit colder than the body the component. This is caused by the heat abstraction of the solder paste and the inside terminals of the capacitor. Therefore, at the beginning of the process, the down-flowing condensate from the leads cools down the condensate layer at the solder joint. Up to $4 \mathrm{~s}$, the temperature of the leads are equalized with the temperature of the component body. However, the heat capacity and heat conductivity of the metal leads is much higher than these parameters of the PET (Tab. 1). This results much more intensive 
condensation on the leads than on the component body. The amount of the down-flowing condensate from the component body is only the $\sim 15 \%$ of the down-flowing condensate from the leads. Therefore, the down-flowing condensate from the sides has minor effect on the temperature of the condensate layer on the PCB (Fig. 6 and 7).

In the second step, the effect of condensate thickness difference between the solder joints was examined on the heating of the solder alloy. The temperature distribution of the PCB and the solder joints can be seen in Fig. 8 a) at $4 \mathrm{~s}$ in the case of $160{ }^{\circ} \mathrm{C}$ preheating and component location $\mathrm{C}$. The solder pads and the solder alloy on them are heating up more rapidly than the other part of the PCB. Under the component, - where the condensation is less intense - the temperature of the PCB is much lower than the average temperature. The edges of the PCB are a bit warmer than the middle because of the thinner condensate at that position locally. Only it is slightly visible, but there is already approximately $2{ }^{\circ} \mathrm{C}$ differences between the solder pads (the left one, closer to the warmer edges). If we are examining the ramp part of the thermal profiles of the solder pads (Fig. 8 b)) the difference becomes more visible. The time difference at onset of the alloy melting between the opposite leads is $924 \mathrm{~ms}$. The phase change of the solder alloy (when the temperature is constant) is relatively long $(\sim 3.5 \mathrm{~s})$ due to the high latent heat of the SAC alloys and the relatively small temperature difference between the liquidus point of the SAC alloys $\left(219^{\circ} \mathrm{C}\right)$ and the boiling point of the LS230 Galden liquid $\left(230^{\circ} \mathrm{C}\right)$.

a) Temperature $\left[{ }^{\circ} \mathrm{C}\right]$

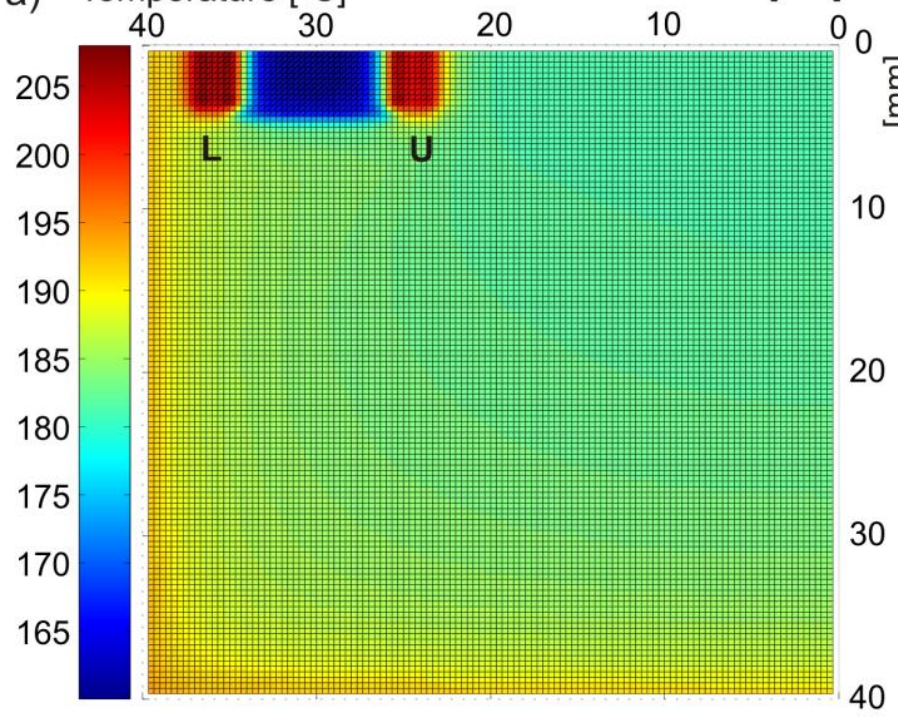

b) Temperature $\left[{ }^{\circ} \mathrm{C}\right]$

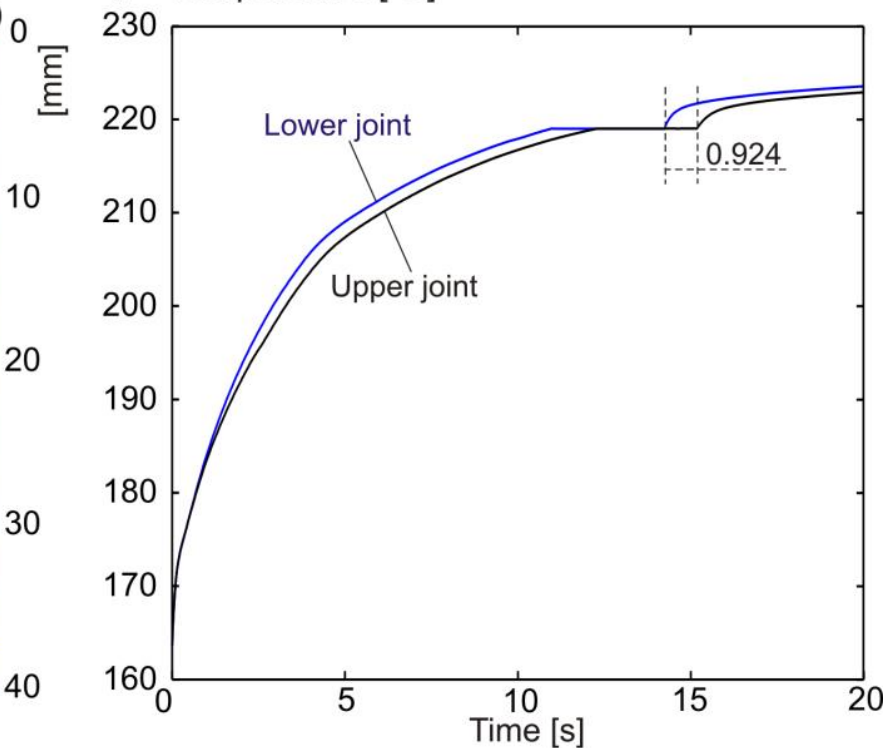


Fig. 8. Temperature of the solder joints: a) temperature distribution of the PCB with $160{ }^{\circ} \mathrm{C}$ soak temperature and component location $\mathrm{B}$ at $4 \mathrm{~s}$; b) ramp part of thermal profile of the solder joints with $160{ }^{\circ} \mathrm{C}$ soak temperature and component location B.

The difference in onset of melting is caused by the difference in the thickness of the condensate between the solder joints during the whole process. Table 2 shows the average differences in the thickness of the condensate and the differences in the onset of melting in the case of different component positions and soak temperatures. At the middle of the PCB (location A and D), the flow of the condensate layer is very slow (compared that at the edges), therefore nor considerable difference in the thickness of condensate, neither significant difference in the onset of melting could form between the solder joints. Oppositely, at the edges of the PCB (location C and F), the flow velocity is very high, which results in considerable differences in the thickness of condensate. This yielded in a difference in onset of melting over $1 \mathrm{~s}$. According to industrial experiences, if this difference is higher than $200 \mathrm{~ms}$, then the possibility of component displacement increases considerably. However, this value can vary from case to case according to the solder joint parameters (component size, pad size, lead design etc). Therefore, we analysed our case in details.

Table 2. The average differences in condensate thickness and in the onset of melting at different component locations and by different soak temperatures.

\begin{tabular}{llll}
\hline $\begin{array}{l}\text { Component } \\
\text { position }\end{array}$ & $\begin{array}{l}\text { Soak temperature } \\
{\left[{ }^{\circ} \mathbf{C}\right]}\end{array}$ & $\begin{array}{l}\text { Avg. condensate } \\
\text { thickness diff. }[\boldsymbol{\mu m}]\end{array}$ & $\begin{array}{l}\text { Onset of melting } \\
\text { diff. }[\mathbf{m s}]\end{array}$ \\
\hline $\mathrm{A}$ & 140 & 15.1 & 114 \\
& 160 & 6.1 & 37 \\
& 180 & 3.2 & 16 \\
\hline $\mathrm{B}$ & 140 & 24.6 & $\mathbf{3 9 9}$ \\
& 160 & 22.4 & 237 \\
& 180 & 19.5 & 178 \\
\hline $\mathrm{C}$ & 140 & 51.4 & $\mathbf{1 4 1 4}$ \\
& 160 & 47.8 & $\mathbf{9 2 4}$ \\
& 180 & 38.5 & $\mathbf{6 2 5}$ \\
\hline $\mathrm{D}$ & 140 & 17.8 & 151 \\
& 160 & 9.5 & 56 \\
& 180 & 5.3 & 27 \\
\hline $\mathrm{E}$ & 140 & 33.6 & $\mathbf{5 3 4}$ \\
& 160 & 24.2 & $\mathbf{3 5 6}$ \\
& 180 & 23.1 & $\mathbf{1 9 6 9}$ \\
\hline $\mathrm{F}$ & 140 & 61.2 & $\mathbf{1 4 7 8}$
\end{tabular}


The applied 2D force model for predicting the component movement during reflow soldering based on the work of Najib et al. [28] - can be seen in Fig. 9.

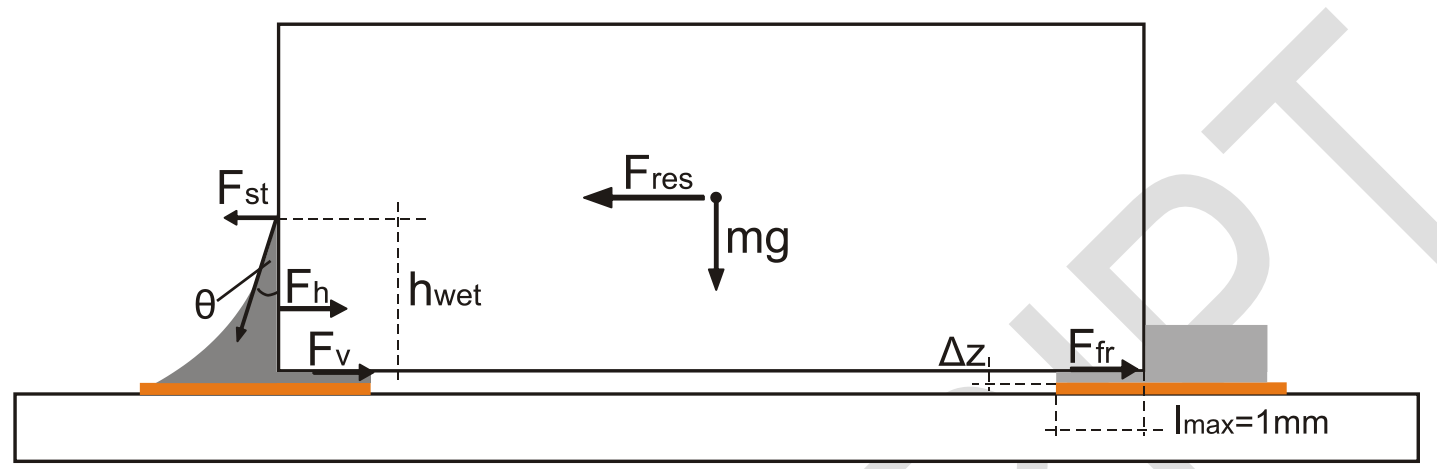

Fig. 9. Force model of the component movement.

The resultant force $\left(F_{\text {res }}\right)$ in the system includes the terms of different forces as follows: the force originating from the surface tension $\left(F_{s t}\right)$ of the liquid solder, which is proportional to the coefficient of surface tension and acting on the triple line of the solder-metallisation-atmosphere (liquid-solidgaseous) phases; the force originating from the hydrostatic pressure of molten solder $\left(F_{h}\right)$ and the viscous force $\left(F_{v}\right)$, which are both acting on the wetted area of the metallisation; the friction force $\left(F_{f r}\right)$ between the component body and the non-melted solder paste at the opposite side of the component. The lateral component of the resultant force can be calculated as:

$$
F_{r e s \mid x, y}=\vec{F}_{s t} \cdot \sin (\Theta)-\vec{F}_{h}-\vec{F}_{v}-\vec{F}_{f r}=\gamma W_{p a d} \cdot \sin (\Theta)-\frac{h_{w e t} \rho g}{2} A_{v_{-} m e t}-\eta \cdot A_{b_{-} m e t} \frac{\partial v}{\partial z}-\mu_{f r} m g
$$

where $\gamma$ is the surface tension $[\mathrm{N} / \mathrm{m}], W_{\text {pad }}$ is the width of the solder pad $[\mathrm{m}], \theta$ is the wetting angle $\left(22^{\circ}\right.$ in the case of SAC305 solder alloy on tin surface finish), $h_{w e t}$ is the dynamic wetting height of the solder $[\mathrm{m}], A_{v_{-} m e t}$ is the wetted area on the face metallisation of the component $\left[\mathrm{m}^{2}\right], \eta$ is the dynamic viscosity $[\mathrm{Pa} \cdot \mathrm{s}], A_{b_{-} m e t}$ is the wetted area on the bottom-side metallisation of the component $\left[\mathrm{m}^{2}\right]$ and $\mu_{f r}$ is the coefficient of friction.

In our case, the maximum movement of the component without the formation of open joint is $l_{\max }=1 \mathrm{~mm}$. According to the series of calculations with different friction constants (between 0.2-0.4), the maximum difference in the onset of solder melting between the opposite-side solder joints - when the component movement is less than $1 \mathrm{~mm}$ - is $300 \mathrm{~ms}$. 
According to the worst-case component positions, the general conclusions of our investigations are the following: the most safe location for large size components is at the middle of the PCB, and not farther from the middle than the half of the characteristic length of the PCB. In this area the possibility component displacement failure due to the difference in the onset of melting is low and does not depend on the component position. Contrary, the probability of the component displacement increases significantly, if the component location is out from the previously defined area; on those locations further analyses are necessary to choose appropriate component position. The effect of the soak temperature is also substantial. If the temperature difference is lower between the soak temperature and the boiling point of the Galden liquid, then the difference in the onset of melting will also be lower and vice versa. If the soak temperature is low $\left(140^{\circ} \mathrm{C}\right.$ or below $)$, then component movement can occur even at locations closer to the middle of the PCB (like B), whereas with higher soak temperatures $\left(180^{\circ} \mathrm{C}\right)$ the component movement can be eliminated even at farther component locations (like E; see in Tab. 2). Therefore, in the case large-size component assembly with VPS soldering, higher soak temperatures $\left(>160^{\circ} \mathrm{C}\right)$ are recommended. It should be noted that higher soak temperatures can be used in VPS technology without the risk of excessive solder paste oxidation; since VPS technology utilises inert atmosphere inherently.

\section{Conclusions}

The condensate layer formation and its effects were investigated around large size SMD components during vapour phase soldering by numerical calculations. The main conclusions are the following: considerable amount of condensate is flowing down from the component at the start of the process, which disturbs the condensate layer on the PCB and has considerable effect on the temperature of the condensate layer at the solder joints. The large heat capacity and heat conductivity of the metal leads cause much more intensive condensation at the leads than on the bare sides of the component body. After some seconds, the temperature of the down-flowing condensate from the component leads exceeds the average condensate layer temperature and heats the surroundings in a considerable manner. The large component body can cause congestion of the condensate layer (depends on the component position) at the component side closer to the centre of the board, which results in considerable condensate layer difference between the solder joints positions with considerable heat transfer differences. Depending on the component location on the PCB and the soak temperature, the difference in the onset of solder alloy melting between the opposite metallization of 
the component can reach even $2 \mathrm{~s}$. In our investigated case, if the difference in onset of melting is over $300 \mathrm{~ms}$, then the probability of any displacement type soldering failure increases considerably; increasing by this the chance of manufacturing with soldering defects.

For reducing the possibility of component displacement failures, the large-size, surface mounted devices should be located closer to the middle of the PCB, and not farther from the middle than the half of the characteristic length of the PCB. Also, the use of higher soak temperatures $\left(>160^{\circ} \mathrm{C}\right)$ is recommended. Further component position analyses are suggested for developing sophisticated PCB design rules for VPS process of large-size SMD components.

\section{Acknowledgement}

This paper was supported by the János Bolyai Research Scholarship of the Hungarian Academy of Sciences.

\section{REFERENCES}

[1] E.J. Kolmes, V.I. Geyko, N.J. Fisch, Heat pump model for Ranque-Hilsch vortex tubes, Int. J. Heat and Mass Transf 107 (2017) 771-777.

[2] S. Li, W. Cai, J. Chen, H. Zhang, Y. Jiang, Numerical study on condensation heat transfer and pressure drop characteristics of ethane/propane mixture upward flow in a spiral pipe, Int. J. Heat and Mass Trans. 121 (2018) 170-186.

[3] V. Kiseev, O. Sazhin, An experimental study of loop heat pipes with steam jet pump, Int. J. Heat Mass Trans 115 (2017) 137-142

[4] F. L. Chang, Y. M. Hung, Dielectric liquid pumping flow in optimally operated micro heat pipes, Int. J. Heat Mass Trans. 108/A (2017) 257-270.

[5] A. Esfandyari, B. Bachy, S. Raithel, A. Syed-Khaja, J. Franke, Simulation, optimization and experimental verification of the over-pressure reflow soldering process, Procedia CIRP 62 (2017) $565-570$.

[6] B. Illés, A. Géczy, Investigating the heat transfer on the top side of inclined printed circuit boards during vapour phase soldering, App. Therm. Eng. 103 (2016) 1398-1407. 
[7] R. P. Nielsen, R. Valsecchi, M. Strandgaard, M. Maschietti, Experimental study on fluid phase equilibria of hydroxyl-terminated perfluoropolyether oligomers and supercritical carbon dioxide, J. Supercrit. Fluids 101 (2015) 124-130.

[8] J. Huang, J. Zhang, L. Wang, Review of vapor condensation heat and mass transfer in the presence of non-condensable gas, App. Therm. Eng. 89 (2015) 469-484.

[9] H.K. Dawood, H.A.Mohammed, N.A.C. Sidik, K.M. Munisamy, M.A.Wahid, Forced, natural and mixed-convection heat transfer and fluid flow in annulus: A review, Inter. Comm. Heat Mass Transf. 62 (2015) 45-57.

[10] B. K. Synkiewicz, A. Skwarek, K. Witek, Voids investigation in solder joints performed with vapour phase soldering (VPS), Solder. \& Surf. Mount. Tech. 26/1 (2014) 8-11.

[11] H. Leicht, A. Thumm, Today's Vapor Phase Soldering - An Optimized Reflow Technology for Lead Free Soldering, in Proceed. of Surf. Mount Tech. Assoc. Intern. Conf., Orlando, USA, 2008, paper No. 45.

[12] G. I. Dumitru, A. Tudor, G. Chisiu, I. Plotog, Mechanical Characteristics of Electronic Printed Circuit Obtained by the Vapour Phase Soldering Process, App. Mech. Mater. 658 (2014) 71-76.

[13] M. Branzei, M. Vladescu, I. Plotog, T. Cucu, Comparative Shear Tests of Two Low Melting Point Solder Pastes Relating to their Thermal Diffusivity, in Proceedings of 40th International Spring Seminar on Electronics Technology (ISSE), Sofia, Bulgaria, 2017, pp 1.-6.

[14] B. Synkiewicz, A. Skwarek, K. Witek, Vapour phase soldering used for quality improvement of semiconductor thermogenerators (TEGs) assembly, Mater. Sci. in Semicond. Process. 38 (2015) $346-351$.

[15] L. Livovsky, A. Pietrikova, Real-time profiling of reflow process in VPS chamber, Solder. Surf. Mount Tech. 29 (2017) 42-48.

[16] G. Finzer, Lötversuch TO263-Mehrpoler auf neuem herstellerunabhängigen Land (Ersatz für 4und 6-Streifenland), Technical Report of Bosch Automobilelektronik, 2004.

[17] N.-C. Lee, Optimizing the reflow profile via defect mechanism analysis, Solder. Surf. Mount Tech. 11 (1999) $13-20$.

[18] K. Dušek, D. Bušek, M. Plaček, A. Géczy, O. Krammer, B. Illés, Influence of vapor phase soldering fluid Galden on wetting forces (tombstone effect), J. Mater. Proc. Tech. 251 (2018) 2025 . 
[19] A.M. Najib, M.Z. Abdullah, A.A. Saad, Z. Samsudin, F. Che Ani, Numerical simulation of selfalignment of chip resistor components for different silver content during reflow soldering, Microelectron. Reliab. 79 (2017) 69-78.

[20] X Zhong, L Chen, B Medgyes, Z Zhang, S Gao, L Jakab, Electrochemical migration of Sn and Sn solder alloys: a review, RSC Advances 7/45 (2017) 28186-28206

[21] N.-C. Lee, Reflow Soldering Process and Troubleshooting, $1^{\text {st }}$ Edition, Newnes, Wobrun, MA, USA, 2008.

[22] S. M. Ramkumar, R. Ghaffarian, A. Varanasi, Lead-free 0201 manufacturing, assembly and reliability test results, Microelectron. Reliab. 46 (2006) 244-262.

[23] A. Bejan, Film condensation on an upward facing plate with free edges, Int. J. Heat Mass Transf. 34(2) (1991) 82-587.

[24] C. Morando, O. Fornaro, O. Garbellini, H. Palacio, Thermal Properties of Sn-based Solder Alloys, J Mater Sci: Mater Electron 25 (2014) 3440-3447.

[25] Q.-Z. Xue, Model for effective thermal conductivity of nanofluids, Physics Letters A 307 (2003) 313-317.

[26] J. Diaza, M. J. Groteb, Multi-level explicit local time-stepping methods for second-order wave equations, Comp. Meth. App. Mech. Eng. 291 (2015) 240-265.

[27] B. Illés, A. Géczy, Investigating the dynamic changes of the vapour concentration in a vapour phase soldering oven by simplified condensation modeling, App. Therm. Eng. 59 (2013) 94-100.

[28] A.M. Najib, M.Z. Abdullah, A.A. Saad, Z. Samsudin, F. Che Ani, Numerical simulation of selfalignment of chip resistor components for different silver content during reflow soldering, Microelectron. Reliab. 79 (2017) 69-78. 